\title{
OPTIMALIZATION OF REACTION TIME THROUGH IMAGERY AND CONCENTRATION TRAINING IN FENCING
}

\author{
Agus Hariyanto $^{1 *}$, Mohammad Wahyu Bagus Prakosa ${ }^{2}$, Anindya Mar'atus Sholikhah ${ }^{3}$ \\ 1Program Studi Pendidikan Kepelatihan Olahraga, Fakultas Ilmu Olahraga, Universitas Negeri Surabaya, Jl. \\ Kampus Unesa Lidah Wetan, Lakarsantri, Surabaya, Indonesia. \\ ${ }^{2}$ Program Studi Pendidikan Olahraga, Pascasarjana Universitas Negeri Surabaya, Jl. Kampus Unesa Lidah \\ Wetan, Lakarsantri, Surabaya, Indonesia. \\ ${ }^{3}$ Program Studi Ilmu Keolahragaan, Fakultas Ilmu Olahraga, Universitas Negeri Surabaya, Jl. Kampus Unesa \\ Lidah Wetan, Lakarsantri, Surabaya, Indonesia. \\ agushariyanto@unesa.ac.id*,mohamadprakosa16070805033@mhs.unesa.ac.id,anindyasholikhah@unesa.ac.id
}

\begin{abstract}
This study aims to investigate the effect of imagery training and concentration on the reaction time of students taking fencing extracurricular activities. It was a quasi-experimental research using quantitative approach. A total of 15 respondents were classified into 3 groups, which were control $(K)$ and two experimental groups. Students in experimental groups were given imagery training (E1) and concentration training (E2) for six weeks and reaction times were measured using Electronic Fencing Target-1 (EFT-1) before and after the exercise was given. Data were analyzed using descriptive and inferential statistic using paired t-test and Anova one way, and significance level was set at $p=0.05$. The results found that the imagery and concentration training had a positive impact on the decrease of reaction time, with significance values of 0.008 and 0.005 , respectively. From these results it can be concluded that imagery and concentration exercises can help players to improve their reaction time, so that fencers can react quickly to every movement.
\end{abstract}

Keywords: concentration; fencing; imagery; training; reaction time

\section{OPTIMALISASI WAKTU REAKSI MELALUI LATIHAN IMAGERY DAN KONSENTRASI DALAM OLAHRAGA ANGGAR}

\begin{abstract}
Abstrak
Penelitian ini bertujuan untuk mengetahui pengaruh latihan imagery dan konsentrasi terhadap kecepatan waktu reaksi pada siswa yang mengikuti ekstrakulikuler anggar. Penelitian ini merupakan penelitian eksperimen semu yang menggunakan pendekatan kuantitatif. Sebanyak 15 orang responden dikelompokkan menjadi 3 kelompok, yaitu satu kelompok kontrol (K) dan dua kelompok eksperimen yang diberi latihan imagery (E1) dan latihan konsentrasi (E2). Latihan dilakukan selama enam minggu dan waktu reaksi diukur sebelum dan sesudah latihan diberikan menggunakan Electronic Fencing Target-1 (EFT-1). Analisis data dilakukan secara deskriptif dan inferensial menggunakan uji paired t-test dan Anova one way, dengan nilai signifikan ditetapkan sebesar 0.05. Hasil analisis didapatkan bahwa latihan imagery dan konsentrasi yang diberikan kepada responden memberikan dampak positif terhadap penurunan waktu reaksi, dengan nilai signifikansi secara berturut-turut sebesar 0.008 dan 0.005. Dari hasil ini dapat disimpulkan bahwa latihan imagery dan konsentrasi dapat membantu pemain untuk meningkatkan kemampuan reaksi, sehingga pemain anggar dapat bereaksi dengan cepat terhadap setiap gerakan.
\end{abstract}

Kata kunci: anggar; imagery; konsentrasi; latihan; waktu reaksi

\section{PENDAHULUAN}

Anggar merupakan salah satu olahraga tertua yang telah dikenal sejak lama (Roi \& Bianchedi, 2008). Pada zaman purbakala dan sebelum dikenal senjata modern, orang-orang 
sudah beranggar dengan menangkis atau menyerang untuk membela diri (Kurniawan, 2010; Supriyoko \& Mahardika, 2018). Di negara barat, anggar merupakan salah satu cabang olahraga yang banyak diminati, dimana olahraga ini banyak diajarkan di sekolah-sekolah Eropa (Rasyono \& Decheline, 2019). Namun di Indonesia, cabang olahraga ini belum begitu populer di kalangan masyarakat luas. Kendati demikian, perkembangan olahraga anggar terus mengalami peningkatan yang cukup signifikan. Hal ini dapat dilihat dari berdirinya pengurus cabang olahraga anggar di beberapa daerah serta adanya kejuaraan nasional yang rutin diselenggarakan setiap tahunnya (Fahrurozi, 2016).

Anggar termasuk jenis olahraga ketangkasan yang memiliki karakteristik khas, yaitu penekanan pada kelincahan tangan dalam menggunakan senjata (Supriyoko \& Mahardika, 2018). Seperti kebanyakan cabang olahraga yang lain, olahraga anggar menuntut pemainnya untuk memiliki keterampilan teknik, taktik dan kemampuan fisik yang baik (Hadjarati, 2010). Dalam permainan anggar, gerakan melangkah maju-mundur, menusuk, menangkis dan menyerang merupakan satu rangkaian gerak yang harus dikuasai oleh seorang pemain. Di samping itu, seorang pemain dituntut untuk mampu melakukan rangkaian gerakan bertahan dan balasan dari serangan lawan supaya memperoleh nilai dari bidang sasaran lawan yang sah (Kontochristopoulos \& Tsolakis, 2019).

Sama seperti catur, seorang pemain anggar dituntut untuk mampu berpikir cepat serta mampu membaca gerakan lawan dan membuat keputusan dalam waktu yang singkat (Turna, 2020). Pemain anggar harus dapat menggunakan waktu sebaik mungkin karena pada momen-momen tertentu, waktu yang dibutuhkan dalam pengambilan keputusan untuk melakukan suatu gerakan atau serangan hanya sepersekian detik (Sorel et al., 2019). Oleh sebab itu, para peneliti sepakat bahwa kecepatan waktu reaksi merupakan hal yang penting dalam menentukan keseluruhan performa pemain anggar dibandingkan cabang olahraga bela diri lainnya (Borysiuk, 2008; Gracz \& Tomczak, 2008). Hal ini disebabkan waktu reaksi yang cepat akan mengurangi total durasi pergerakan, yang pada akhirnya membuat pemain lebih cepat dalam melakukan serangan atau gerakan bertahan. Berdasarkan hal tersebut, maka penting untuk diketahui bahwa selain dituntut untuk memiliki kondisi fisik dan teknik yang baik, pemain anggar juga dituntut untuk memiliki mental dan konsentrasi yang baik pula agar dapat meningkatkan kecepatan waktu reaksi saat bermain.

Dalam penelitiannya, Purnama (2014) menyebutkan bahwa faktor non-teknis atau psikologi sangat mempengaruhi performa seorang pemain anggar baik saat berlatih maupun saat bertanding. Kelemahan dalam faktor psikologis akan berdampak besar terhadap kematangan fisik, teknik, dan taktik seorang atlet dimana atlet yang tidak bisa mengelola mentalnya dengan baik tidak akan dapat mengeluarkan kemampuannya secara maksimal (Fahrurozi, 2016; Herfiantoro, 2019). Beberapa penelitian terdahulu menyatakan bahwa faktor-faktor psikologis yang dapat mempengaruhi performa atlet antara lain fokus dan konsentrasi, kemampuan coping terhadap distraksi, kontrol terhadap emosi, dan mental imagery (Bertollo et al., 2009).

Latihan mental atau mental training merupakan hal yang penting bagi atlet untuk dapat mencapai prestasi gemilang (Fitria, 2018; Suryanto, 2015). Beberapa contoh latihan mental yang dapat dilakukan untuk meningkatkan performa atlet yaitu visualisasi, self-hypnosis, self-talk, relaksasi, dan imagery (Wibowo \& Rahayu, 2016; Novita Indra, RR.Wijayanti, 2015). Di antara bentuk latihan mental tersebut, imagery training merupakan salah satu bentuk latihan yang sering diterapkan untuk meningkatkan performa atlet di berbagai cabang olahraga, seperti bolabasket, bola voli, karate, tenis, dan anggar. Imagery training merupakan serangkaian proses pembinaan mental atlet yang melibatkan semua unsur panca indera untuk meningkatkan fokus, konsentrasi, serta mengarahkan tindakan ke suatu tujuan (Septiyanto \& Suharjana, 2016). Latihan imagery memiliki peranan penting untuk membantu atlet atau pemain dalam meningkatkan keterampilan gerak. Latihan ini dapat 
menciptakan kembali pengalaman gerak atlet di dalam otaknya, dengan serangkaian proses mengingat pola gerak secara berulang-ulang sehingga memungkinkan atlet untuk dapat melakukan kembali pola gerakan tersebut (Wibowo \& Rahayu, 2016).

Berbagai macam metode latihan telah dikembangkan untuk meningkatkan performance pemain anggar, khususnya untuk mempercepat waktu reaksi (Turna \& Kılınç, 2016). Namun berdasarkan yang penulis ketahui, belum banyak studi yang meneliti tentang latihan imagery dan konsentrasi. Padahal di dalam olahraga anggar, latihan imagery memiliki peranan penting dalam membantu pemain untuk meningkatkan keterampilan gerak tangan menuju titik sasaran sehingga senjata dapat menusuk bidang sasaran dengan tepat. Selain itu, latihan imagery juga dapat meningkatkan kemampuan reaksi, sehingga pemain anggar dapat bereaksi dengan cepat terhadap setiap gerakan. Oleh sebab itu, dilakukanlah penelitian ini untuk mengetahui pengaruh latihan imagery dan konsentrasi terhadap waktu reaksi pemain anggar.

\section{METODE}

Penelitian ini merupakan penelitian eksperimen semu yang menggunakan pendekatan kuantitatif. Partisipan dalam penelitian ini adalah seluruh siswa yang mengikuti ekstrakurikuler anggar di SMA Muhammadiyah 3 sebanyak 15 orang. Pemilihan partisipan didasarkan pada asumsi bahwa siswa yang mengambil ekstrakulikuler anggar telah familiar terhadap permainan anggar, sehingga dirasa sesuai untuk memenuhi kebutuhan penelitian ini. Responden kemudian dibagi ke dalam tiga kelompok, yaitu satu kelompok kontrol (K) dan dua kelompok eksperimen (E1 dan E2) yang masing-masing berisi 5 orang. Penentuan anggota sampel menggunakan metode ordinal pairing, agar diperoleh susunan berdasarkan jenjang dalam atribut tertentu. Ordinal pairing merupakan salah satu cara untuk mengelompokkan sampel dengan menggunakan sistem urutan yang menggambarkan adanya peringkat.

Setelah dibagi, masing-masing kelompok dilakukan pengukuran terhadap waktu reaksi menggunakan Favero Electronic Fencing Target-1. Selanjutnya, pada kelompok eksperimen 1 (E1), responden diberi perlakuan berupa latihan imagery dan pada kelompok eksperimen 2 (E2), diberi perlakuan berupa konsentrasi, sedangkan kelompok kontrol tidak diberi program latihan. Latihan imagery dilakukan dengan menginstruksikan responden untuk membayangkan gerakan yang dipraktikkan sebelumnya oleh instruktur. Sedangkan latihan konsentrasi dilakukan dengan memberi instruksi kepada responden untuk fokus mencari satu objek. Setelah ditemukan, objek tersebut kemudian diganti menjadi objek yang lain secara berurutan hingga responden bisa memiliki konsentrasi yang baik. Setelah enam minggu melakukan latihan, dilakukan pengukuran kembali terhadap waktu reaksi terhadap masing-masing kelompok

Analisis data dilakukan secara deskriptif dan inferensial. Statistik deskriptif ditulisan ke dalam nilai rata-rata dan standar deviasi, sedangkan statistik inferensial menggunakan paired t-test dan Anova one way untuk mengetahui perbedaan nilai pretest dan posttest dari masing-masing kelompok. Analisis statistik dilakukan dengan nilai signifikansi yang ditetapkan sebesar 5\%.

\section{HASIL DAN PEMBAHASAN}

Penelitian ini bertujuan untuk mengetahui ada tidaknya pengaruh latihan imagery terhadap kecepatan waktu reaksi. Hasil analisis deskriptif disajikan pada Tabel 1 berikut. 
MEDIKORA, Vol. 20 No. 1 April 2021 - 39

Muhammad Sigit Antoni, Guntur, Rifqi Festiawan, Arifin Ika Nugraha, Farid Imam Nurhadi

Tabel 1. Hasil Analisis Deskriptif Terhadap Waktu Reaksi

\begin{tabular}{|l|c|c|c|}
\hline \multirow{2}{*}{ Kelompok } & \multirow{2}{*}{$\mathbf{n}$} & \multicolumn{2}{c|}{ Waktu Reaksi* } \\
\cline { 3 - 4 } & & Pre & Post \\
\hline Imagery (E1) & 5 & $0.99 \pm 0.08$ & $0.91 \pm 0.07$ \\
\hline Konsentrasi (E2) & 5 & $0.86 \pm 0.04$ & $0.81 \pm 0.05$ \\
\hline Kontrol (K) & 5 & $1.02 \pm 0.09$ & $0.96 \pm 0.06$ \\
\hline
\end{tabular}

*disajikan dalam mean $\pm S D$ (dalam detik)

Hasil analisis deskriptif pada Tabel 1 menunjukkan adanya perbedaan rerata kecepatan waktu reaksi sebelum dan sesudah diberi perlakuan pada masing-masing kelompok. Pada kelompok E1, waktu reaksi mengalami penurunan dari $0.99 \pm 0.08$ menjadi $0.91 \pm 0.07$. Penurunan juga dijumpai pada kelompok E2, yang mana waktu reaksi responden mengalami penurunan setelah diberi latihan konsentrasi, yakni dari $0.86 \pm 0.04$ menjadi $0.81 \pm 0.05$.

Tabel 2. Hasil Uji Normalitas

\begin{tabular}{|l|c|c|c|c|}
\hline \multirow{2}{*}{ Kelompok } & \multirow{2}{*}{$\mathbf{n}$} & \multicolumn{2}{c|}{$p$-value } & \multirow{2}{*}{ Keterangan } \\
\cline { 3 - 4 } & & Pretest & Posttest & \\
\hline Imagery (E1) & 5 & 0.871 & 0.715 & Normal \\
\hline Konsentrasi (E2) & 5 & 0974 & 0.958 & Normal \\
\hline Kontrol (K) & 5 & 0.699 & 0.709 & Normal \\
\hline
\end{tabular}

Hasil uji normalitas pada Tabel 2 menunjukkan bahwa kelompok yang diberi latihan imagery (E1), konsentrasi (E2), dan kelompok kontrol memiliki distribusi yang normal ( $\mathrm{p}>$ 0.05). Oleh sebab itu, analisis dapat dilanjutkan menggunakan uji parametrik.

Tabel 3. Hasil Uji Pengaruh Latihan Imagery terhadap Waktu Reaksi

\begin{tabular}{|l|c|c|c|c|}
\hline \multicolumn{1}{|c|}{ Kelompok } & n & Mean \pm SD & t & p-value \\
\hline Imagery (E1) & 5 & $0.074 \pm 0.034$ & 4.922 & $0.008^{*}$ \\
\hline Konsentrasi (E2) & 5 & $0.048 \pm 0.019$ & 5.580 & $0.005^{*}$ \\
\hline Kontrol (K) & 5 & $0.062 \pm 0.071$ & 1.947 & 0.123 \\
\hline
\end{tabular}

*signifikan pada $p=0.05$

Berdasarkan hasil uji beda menggunakan paired t-test (Tabel 3), nilai signifikansi pada kelompok yang diberi latihan imagery (E1), konsentrasi (E2), dan kelompok kontrol secara berturut-turut adalah 0.008, 0.005, dan 0.123. Sehingga, dapat disimpulkan bahwa perlakuan berupa latihan imagery dan konsentrasi yang diberikan kepada responden memberikan dampak positif terhadap penurunan waktu reaksi.

Tabel 4. Perbedaan Pengaruh Jenis Latihan terhadap Waktu Reaksi

\begin{tabular}{|l|l|c|c|}
\hline \multicolumn{2}{|c|}{ Kelompok } & $\Delta$ Mean & p-value \\
\hline Imagery (E1) & Konsentrasi (E2) & 0.098 & $0.003^{*}$ \\
& Kontrol & -19.250 & $0.000^{*}$ \\
\hline Konsentrasi (E2) & Imagery (E1) & -0.098 & $0.003^{*}$ \\
& Kontrol & -19.348 & $0.004^{*}$ \\
\hline Kontrol & Imagery (E1) & 19.250 & $0.000^{*}$ \\
& Konsentrasi (E2) & 19.348 & $0.004^{*}$ \\
\hline
\end{tabular}

*signifikan pada $p=0.05$ 
Dari hasil uji beda menggunakan Anova one-way diketahui bahwa jenis latihan yang diberikan kepada responden memberikan perbedaan yang signifikan terhadap waktu reaksi. Dan dari hasil uji lanjutan menggunakan post hoc dapat disimpulkan bahwa waktu reaksi dari responden yang tidak diberi latihan apapun (kontrol) ternyata berbeda secara signifikan dibandingkan dengan responden yang diberi latihan imagery (E1) dan konsentrasi (E2), dengan nilai signifikansi secara berturut-turut sebesar 0.000 dan 0.004 .

Penelitian ini dilakukan untuk melihat pengaruh jenis latihan yang diberikan terhadap waktu reaksi pemain anggar. Jenis latihan yang diberikan adalah latihan imagery dan konsentrasi, yang mana kedua latihan ini sangat berkaitan dengan aspek psikologis pemain atau atlet. Dalam permainan anggar, aspek psikologis atau mental merupakan hal yang penting, sebab keadaan emosi dapat mempengaruhi kualitas tangkisan, serangan, dan kecepatan dalam menghindar (waktu reaksi) (Barth \& Beck, 2007; Fahrurozi, 2016). Namun selain terkait dengan aspek psikologis, waktu reaksi atau response time juga merupakan bagian yang tak terpisahkan dari kemampuan seorang atlet atau pemain, di samping kecepatan, kelincahan, keakuatan, kesimbangan, dan koordinasi (Aktaş et al., 2019; Çakmakçı et al., 2019). Sehingga, dapat dikatakan bahwa keberhasilan dan kegagalan pemain dalam bertanding sangat ditentukan oleh keseimbangan antara kemampuan fisik dan kondisi psikologisnya (Kubiak, 2012; Pulungan \& Dimyati, 2019).

Hasil penelitian ini menunjukkan bahwa latihan imagery dan konsentrasi memberikan dampak terhadap penurunan waktu reaksi $(\mathrm{p}<0.05)$. Temuan ini sesuai dengan hasil penelitian yang dilakukan oleh Anggraeni et al., (2018) dan Iftikhar et al., (2018) yang menyatakan bahwa latihan imagery berpengaruh terhadap waktu reaksi. Melalui latihan imagery, seorang atlet atau pemain dapat membangun kepercayaan dirinya sekaligus membantu dalam mempersiapkan performa terbaik di lapangan. Latihan ini juga memungkinkan pemain unttk meninjau skill dan gerakan sebelumnya, sehingga mereka dapat memperbaiki kesalahan (Iftikhar et al., 2018). Atas pertimbangan inilah latihan imagery banyak digunakan oleh atlet, dimana sebanyak 70-90\% atlet professional rutin berlatih imagery untuk meningkatkan performanya (Mizuguchi et al., 2012).

Penelitian yang dilakukan terhadap siswa SMP sebelumnya menyebutkan bahwa latihan imagery dapat memberikan pengalaman gerak fisik yang lebih mendalam sekaligus dapat meningkatkan pengalaman gerak pada kognitif siswa. Dampaknya, siswa akan merasa lebih mudah untuk menguasai gerakan yang sulit dan kompleks (Abdillah et al., 2019). Dalam penelitian, ini kelompok yang diberi perlakuan berupa latihan imagery memiliki waktu reaksi yang lebih cepat dibandingkan kelompok kontrol. Hal ini menunjukkan bahwa siswa sudah terbiasa untuk mengulang-ulang gerakan di dalam pikirannya, sehingga ketika dipraktikkan, mereka bisa memberikan reaksi yang lebih cepat.

Namun, kecepatan bereaksi juga tidak lepas dari kemampuan atlet untuk berkonsentrasi. Temuan dalam penelitian ini menunjukkan bahwa kelompok siswa yang diberi perlakuan berupa latihan konsentrasi memiliki waktu reaksi yang lebih cepat dibandingkan siswa yang tidak mendapat perlakuan apa-apa. Dalam anggar, seorang pemain dituntut untuk bisa mengambil keputusan dengan cepat terhadap setiap gerakan yang terjadi (Reigal et al., 2019). Dalam hal ini, konsentrasi sangat diperlukan agar pemain bisa memusatkan fokus dan seluruh perhatiannya sehingga ia dapat merespon setiap stimulus, serangan atau tangkisan yang dilakukan oleh lawan dengan cepat. Anggar merupakan olahraga dengan gerakan yang sangat cepat, sehingga kunci dalam permainan ini terletak pada kemampuan untuk mengenali area target dan membaca pergerakan lawan dalam waktu yang singkat (Hijazi, 2013).

Kecepatan waktu reaksi berkaitan dengan pemrosesan rangsangan visual atau taktil, koordinasi otot selama gerakan, serta kondisi mental yang baik merupakan faktor dasar yang menentukan keseluruhan performa dalam olahraga anggar (Balkó et al., 2016). Pemain 
anggar yang memiliki kecepatan bereaksi yang baik akan mudah dalam menangkis serangan lawan dan pada saat menyerang akan membuat lawan kesulitan untuk menghindar (Sarihudin, 2016). Waktu reaksi juga turut menentukan total durasi yang dibutuhkan pemain untuk melakukan gerakan-gerakan tertentu. Dengan kata lain, waktu pergerakan secara keseluruhan dalam olahraga tertentu seperti tinju, karate, atau anggar dapat dipersingkat dengan reaksi yang semakin cepat (Balkó et al., 2017). Dalam olahraga tersebut, waktu reaksi juga turut menentukan kemenangan, dimana semakin kecil waktu atau semakin cepat pemain memberikan reaksi maka dialah yang memiliki peluang lebih besar untuk menang (Tatlici et al., 2018). Dengan demikian, pemain dan pelatih anggar perlu untuk memperhatikan faktor-faktor yang dapat meningkatkan waktu reaksi sehingga atlet atau pemain dapat menampilkan performa terbaiknya di lapangan.

\section{SIMPULAN}

Dari penelitian yang telah dilakukan, dapat disimpulkan bahwa penerapan latihan imagery dan konsentrasi terbukti dapat meningkatkan kecepatan waktu reaksi pada siswa yang mengikuti ekstrakulikuler anggar. Keterbatasan dalam penelitian ini adalah jumlah sampel yang kecil sehingga hasil penelitian tidak dapat digeneralisasikan untuk pemain anggar secara keseluruhan. Selain itu dalam penelitian ini tidak memperhatikan faktor karakteristik subyektif dari responden yang mungkin dapat mempengaruhi hasil penelitian. Oleh sebab itu, dalam penelitian selanjutnya perlu memasukkan karakteristik subyektif sebagai variabel sehingga penelitian dapat memberikan hasil yang lebih baik.

\section{DAFTAR PUSTAKA}

Abdillah, Simanjuntak, V. G., \& Triansyah, A. (2019). Pengaruh metode latihan imagery terhadap ketepatan sepak mula dalam permainan sepak takraw. Jurnal Pendidikan Dan Pembelajaran Khatulistiwa, 8(10), 1-9.

Aktaş, S., Tatlici, A., \& Çakmakçi, O. (2019). Determination of Isokinetic Strength of Upper and Lower Body of Elite Male Boxers. Turkish Journal of Sport and Exercise, 21(2), 188-191. https://doi.org/10.15314/tsed.600645

Anggraeni, P., Rumadi, \& Vai, A. (2018). The effect of exercise imagery to the speed of reaction team pencak silat perisai diri Pekanbaru. JOM FKIP, 5.

Balkó, S., Borysiuk, Z., \& Simonek, J. (2016). The Influence of Different Performance Level of Fencers on Simple and Choice Reaction Time. Revista Brasileira de Cineantropometria e Desempenho Humano, 18(4). https://doi.org/10.5007/19800037.2016v18n4p391

Balkó, S., Rous, M., Balkó, I., Hnízdil, J., \& Borysiuk, Z. (2017). Influence of a 9-week training intervention on the reaction time of fencers aged 15 to 18 years. Physical Activity Review, 5, 146-154. https://doi.org/10.16926/par.2017.05.19

Barth, B., \& Beck, E. (2007). The Complete Guide to Fencing (First). Meyer \& Meyer Verlag.

Bertollo, M., Saltarelli, B., \& Robazza, C. (2009). Mental preparation strategies of elite modern pentathletes. Psychology of Sport and Exercise, 10(2), 244-254. https://doi.org/10.1016/j.psychsport.2008.09.003

Borysiuk, Z. (2008). Psychomotor Reactions in Fencing Dependence of Stimuli Type. Rev Bras Cineantropom Desempenho Hum, 10(3), 223-229. https://doi.org/10.5007/19800037.2008v10n3p223

Çakmakçı, E., Tatlici, A., Kahraman, S., Yilmaz, S., Ünsal, S., \& Özkaymakoğlu, C. (2019). Does once-a-week boxing training improve strength and reaction time? Uluslararast 
MEDIKORA, Vol. 20 No. 1 April 2021 - 42

Muhammad Sigit Antoni, Guntur, Rifqi Festiawan, Arifin Ika Nugraha, Farid Imam Nurhadi

Spor Egzersiz ve Antrenman Bilimi Dergisi, 5(2), 88-92. https://doi.org/10.18826/useeabd.552086

Fahrurozi, A. F. (2016). Hubungan Kecerdasan Emosional dengan Kemampuan Bereaksi pada Olahraga Anggar di UKM Anggar UPI. Universitas Pendidikan Indonesia.

Fitria, F. (2018). Pengaruh Latihan Imagery dan Self-Talk Terhadap Konsentrasi dan Ketepatan Tusukan Dalam Permainan Anggar. Jendela Olahraga, 3(2), 19-25. https://doi.org/10.26877/jo.v3i2.2429

Gracz, J., \& Tomczak, M. (2008). Selected Temperamental Properties and Achievement Motivation of Fencers. Studies in Physical Culture and Tourism, 15(2), 109-118.

Hadjarati, H. (2010). Metodik Melatih Anggar (Ruslan \& M. Tahala (eds.)). Penerbit FIKK UNG.

Herfiantoro, A. (2019). Pengaruh Latihan Imagery dan Kecerdasan terhadap Tingkat Kecemasan Atlet Club Atletik Glagah Wangi Demak. Universitas Negeri Semarang.

Hijazi, M. M. K. (2013). Attention, Visual Perception and their Relationship to Sport Performance in Fencing. Journal of Human Kinetics, 39, 195-201. https://doi.org/10.2478/hukin-2013-0082

Iftikhar, M. T., Mallett, C. J., \& Javed, M. A. (2018). Imagery improves reaction time in elite srinters. 6th International Congress on Sport Sciences Research and Technology Support, 27-33. https://doi.org/10.5220/0006898300270033

Kontochristopoulos, N., \& Tsolakis, C. (2019). Offensive and defensive efficacy among male and female elite foil fencers. Journal of Human Sport and Exercise, 15(2), 1-9. https://doi.org/10.14198/jhse.2020.152.05

Kubiak, C. (2012). Perceived factors influencing athletic performance across career stages. Halmstad University.

Kurniawan, F. (2010). Mengenal Cabang Olahraga Klasik, Anggar. UNY Press.

Mizuguchi, N., Nakata, H., Uchida, Y., \& Kanosue, K. (2012). Motor imagery and sport performance. The Journal of Physical Fitness and Sports Medicine, 1(1), 103-111. https://doi.org/10.7600/jpfsm.1.103

Novita Indra, RR.Wijayanti, E. (2015). OUTBOUND SEBAGAI MEDIA ALTERNATIF UNTUK MENINGKATKAN KETERAMPILAN PSIKOLOGIS PADA ATLET. MEDIKORA, 9(1). https://doi.org/10.21831/medikora.v0i1.4647

Pulungan, K. A., \& Dimyati. (2019). Karakteristik keterampilan psikologis pemain bolavoli Indonesia ditinjau berdasarkan gender dan posisi The psychological skill characteristics of Indonesian volleyball players reviewed based on gender and position PENDAHULUAN Olahraga prestasi dilaksanaka. Jurnal SPORTIF: Jurnal Penelitian Pembelajaran, 5(1), 279-295. https://doi.org/10.29407/js_unpgri.v5i2.13178

Purnama, D. (2014). Perbandingan Kualitas Teknik Antara Elit Atlet Nasional dan Elit Atlet Internasional Nomor Sabel Putra Perorangan dalam Olahraga Anggar dengan Menggunakan Notational Analysis Method: Studi Deskriptif pada Elit Atlet Anggar Nasional dan Internasional. Universitas Pendidikan Indonesia.

Rasyono, R., \& Decheline, G. (2019). Pengaruh Variasi Latihan Serangan Terhadap Ketepatan Tusukan Atlet Anggar Provinsi Jambi. Altius: Jurnal Ilmu Olahraga Dan Kesehatan, 8(2), 28-34. https://doi.org/10.36706/altius.v8i2.8895 
Reigal, R. E., Barrero, S., Martin, I., \& Al, E. (2019). Relationships Between Reaction Time, Selective Attention, Physical Activity, and Physical Fitness in Children. Frontiers in Psychology, 10(2278). https://doi.org/10.3389/fpsyg.2019.02278

Roi, G. S., \& Bianchedi, D. (2008). The Science of Fencing: Implications for Performance and Injury Prevention. Sports Medicine, 38(6), 465-481.

Sarihudin, L. O. (2016). Hubungan Reaction Time dan Coordination dengan Hasil Serangan Langsung pada Atlet UKM Anggar UPI. Universitas Pendidikan Indonesia.

Septiyanto, A., \& Suharjana, S. (2016). Pengaruh Metode Latihan Imagery dan Konsentrasi Terhadap Ketepatan Floating Service Atlet Bola Voli DIY. Jurnal Cakrawala Pendidikan, 35(3), 412-420. https://doi.org/10.21831/cp.v35i3.8249

Sorel, A., Plantard, P., Bideau, N., \& Pontonnier, C. (2019). Studying fencing lunge accuracy and response time in uncertain conditions with an innovative simulator. PLOS ONE, 14(7). https://doi.org/10.1371/journal.pone.0218959

Supriyoko, A., \& Mahardika, W. (2018). Kondisi Fisik Atlet Anggar Kota Surakarta. SPORTIF: Jurnal Penelitian Pembelajaran, 4(2), 280-292.

Suryanto, S. (2015). IDENTIFIKASI KONDISI PSIKOLOGIS (MENTAL) PEMANAH JUNIOR DI DIY. MEDIKORA, VII(1). https://doi.org/10.21831/medikora.v0i1.4659

Tatlici, A., Çakmakçı, E., Yilmaz, S., \& Arslan, F. (2018). Comparison of Visual Reaction Values of Elite Deaf. Turkish Journal of Sport and Exercise, 20(22), 63-66. https://doi.org/10.15314/tsed.440813

Turna, B. (2020). The Effect of Agility Training on Reaction Time in Fencers. Journal of Education and Learning, 9(1), 127. https://doi.org/10.5539/jel.v9n1p127

Turna, \& K1lınç, F. (2016). "Examining the Relation Between the Performance Levels of the Footballers and the Data Obtained with the Routine" Combined Performance Analyses. Us-China Education Review, 6, 657-668. https://doi.org/10.17265/2161623X/2016.11.005

Wibowo, S. A. P., \& Rahayu, N. I. (2016). Pengaruh Latihan Mental Imagery Terhadap Hasil Tembakan Atlet Menembak Rifle Jawa Barat. Jurnal Terapan Ilmu Keolahragaan, 1(2), 23. https://doi.org/10.17509/jtikor.v1i2.2776 